\title{
Mental health, subjective well-being, and religiosity: Significant associations in Kuwait and USA ${ }^{1}$
}

\author{
Ahmed Abdel-Khalek \\ Kuwait University \\ David Lester \\ Richard Stockton College of New Jersey
}

\begin{abstract}
This paper explores the associations between mental health, subjective wellbeing, and religiosity among Kuwaiti and American college students. Our method involved recruiting two convenience samples of 154 Kuwaiti and 154 American undergraduates (28 men, 125 women in both samples), with a mean age of 20.8 yr. $(S D=2.4)$, and $21.8(S D=5.0)$, respectively. They completed the Arabic Scale of Mental Health (ASMH), the Rosenberg Self-Esteem Scale, the Arabic Scale of Optimism and Pessimism, the Hopelessness Scale, and self-rating scales assessing physical health, mental health, and religiosity. The scales were administered in Arabic to the Kuwaiti students and in English to the American students.

Kuwaiti students obtained a significantly higher mean score on religiosity than did their American counterparts, whereas American students had higher mean scores on the ASMH, and the self-rating scales of both mental health and physical health. Significant correlations were found between the ASMH, self-esteem, optimism and religiosity (positive), whereas the correlations between these scales and pessimism and hopelessness were negative. Two factors were retained in both countries: "Mental health versus hopelessness" and "Self-ratings of religiosity and health". Predictors of ASMH were optimism, self-esteem and the selfrating of mental health in both countries and, in addition, hopelessness (negative) and religiosity in the American sample.
\end{abstract}

1. Correspondence: Email (david.lester@stockton.edu). 
Keywords: Mental health, subjective well-being, religiosity, self-esteem, optimism, pessimism, hopelessness, Christian, Muslim.

Within contemporary psychology, there are at least three interesting developments: an increasing interest in religion and spirituality; globalization of the field, including an increasing number of international conferences and crosscultural programs of research; and, most recently, positive psychology (AbdelKhalek \& Scioli, 2010). The present research is relevant to these three features.

The general objective of this study was to investigate the associations between mental health, subjective well-being (SWB), and religiosity in two different cultures, Kuwait and the USA. Many research articles, review articles and books have documented the positive relationship between SWB, health, and religiosity (e.g., Hill \& Pargament, 2003; Koenig, King, \& Carson, 2012; Larson \& Larson, 2003). However, cross-cultural studies on this association are rare (Furnham \& Cheng, 1999). Even research using non-English speaking populations is scarce, especially Arab Muslim samples. This research tries to fill the gap.

Good mental health has two main components: an absence of negative symptoms and positive signs of psychological and psychiatric functioning. The second component includes positive indicators such as functioning at a high level of adaptation, having fulfilling social relationships with other people, mental balance, self-esteem, self-control, maturity, and resilience. Mental health is indispensable to SWB, and SWB is the positive side of mental health.

SWB can be defined as people's cognitive and affective evaluations of their lives. These evaluations include emotional reactions to events as well as cognitive judgments of satisfaction and fulfillment. SWB is a broad concept that includes experiencing pleasant emotions, low levels of negative moods, and a high level of life satisfaction (Diener, Lucas, \& Oishi, 2002, p. 63). Diener (1998) considered SWB as "the psychological term for what in popular parlance is referred to as happiness" (p. 311; see also Argyle, 2002; Diener, Oishi, \& Lucas, 2003; Seligman \& Csikszentmihalyi, 2000).

Veenhoven (2010) used the word "happiness" in the widest sense, as an umbrella term for all that is good. It is often used interchangeably with terms like "well-being" or "quality of life." He stated that happiness is commonly understood as how much one likes the life one lives or, more formally, the degree to which one evaluates positively one's life as a whole (Veenhoven, 2009). Argyle, Martin, and Lu (1995) proposed three possible components of happiness: positive emotion, satisfaction, and the absence of negative emotions such as depression or anxiety. Generally speaking, SWB includes happiness, joy, satisfaction, enjoyment, fulfillment, pleasure, and contentment. SWB exists on a continuum, ranging from states of very low well-being (including severe depression and hopelessness) to those of very high well-being (genuine happiness). 
A substantial body of research reports a positive association between religiosity, mental health, and SWB (e.g., Dezutter, Soenens, \& Hutsebaut, 2006; Lavric \& Flere, 2008; Rew \& Wong, 2006; Seybold, 2007). For example, Jensen, Jensen, and Wiederhold (1993) found a positive association between religiosity and mental health measured with three scales: depression, emotional maturity, and self-esteem. In a related vein, Roman and Lester (1999) found a negative association between religiosity and psychoticism. Ringdal (1996) found that religiosity was significantly related to general satisfaction with life and feelings of hopelessness among 253 hospitalized cancer patients between the ages 23 and 78 years old.

Wong, Rewand Slaikeu (2006) reviewed studies using adolescents and found that most of the studies (90\%) showed that higher levels of religiosity/ spirituality were associated with better mental health. Existential dimensions of religiosity/spirituality had the most robust relationship with mental health, and the association was generally stronger for males and older adolescents than for females and younger adolescents.

Regarding the association between religiosity and self-esteem, some studies indicate that religious involvement bolsters feelings of self-esteem (e.g., Abdel-Khalek, 2011a). In the same vein, Evers (2009) found that religiosity buffered the risk of poor self-esteem and depression in a sample of alternative high school students at risk for dropping out of school. Husain (2008) studied 131 Somali youth in the United States and found that religiosity was correlated with self-esteem and school grades. However, there are conflicting results. In contrast with the research mentioned above, Donahue and Benson (1995) found no significant relationship between religiosity and self-esteem in a national study of some 30,000 American adolescents. Despite these results, the number of studies reporting a positive relationship between religiosity and self-esteem outnumber those reporting a negative association.

As for the relationship between religiosity and optimism, a growing number of research studies indicate that religiosity is positively associated with optimism and negatively with pessimism (e.g., Abdel-Khalek \& Lester, 2006b). This association was found in women but not men in Algeria (Abdel-Khalek \& Naceur, 2007). Schutte and Hosch (1996) found that religiosity predicted optimism while both religiosity and optimism predicted neuroticism in MexicanAmerican samples, but not in Anglo-American and Mexican national samples. However, Möller and Reimann (2004) found that an optimistic perception of one's own future was unrelated to religiosity.

Ali (2007) recruited 300 Pakistani Muslims in the United States and found significant positive correlations between SWB and religiosity, ethnic identity, and non-religious social activity and between generational status and acculturation. Multiple regression analyses revealed that the best predictor of SWB for this sample was religiosity, followed by ethnic identity and socioeconomic status. 
In Japan, using a non-Christian sample, Roemer (2009) found strong positive correlations between life satisfaction and happiness (SWB) and religious affiliation and devotion. He proposed that religiosity is multidimensional and that different dimensions impact Japanese well-being in diverse ways. Rutledge (2010), using an adult community sample, found that organized religiosity to be the only religious measure significantly correlated with and predictive of SWB. He concluded that religion's benefits are grounded in the social dimension of religion such as participation in organized public religious activities.

It is worth mentioning, however, that there are studies that do not find a positive association between religiosity and SWB, or that have found a negative correlation (e.g., Francis, Ziebertz, \& Lewis, 2003; Lewis, 2002). For example, Lewis, Maltby, and Day (2005) did not find a significant association between religiosity scores and happiness scores among British adults. However, they found that both higher intrinsic orientation scores and positive religious coping scores were significantly associated with higher scores of happiness as assessed with the short form of the Oxford Happiness Questionnaire. They proposed that these differential findings are consistent with the theoretical distinction between subjective and psychological well-being. They suggested that, when religiosity is related to happiness, it is related to psychological wellbeing, which is thought to reflect human development, positive functioning, and existential life challenges. However, the number of studies yielding positive relations between SWB and religiosity overshadow the number of studies with negative results.

The vast majority of studies on this topic have been carried out in Englishspeaking populations. However, a limited number of studies have been carried out on the relationship between religiosity and both SWB and psychopathology using Muslim participants in Kuwait, Saudi Arabia, Algeria, and Egypt. For example, Tiliouine, Cummins, and Davern (2009), using an Islamic Religiosity Scale with 2,909 Muslims from Algeria, found that individuals with high scores on religious practice had higher scores on personal well-being.

Using a sample of 495 Muslim students from Algeria, Tiliouine and Belgoumidi (2009) found that religious belief and religious altruism significantly contributed to providing subjects with a meaning in life. Hierarchical regression analyses showed that only religious belief made a significant contribution to both satisfaction with life and a personal well-being index.

The main results of these studies are two-fold: (a) there is a positive relationship between religiosity and SWB, including happiness, satisfaction with life, love of life, physical health, and mental health; and (b) there is a negative relationship between religiosity and psychopathology, such as anxiety and depression. It is important to note also that Thorson, Powell, Abdel-Khalek, and Beshai (1997) compared Kuwaiti and American college students and found that the Kuwaiti sample obtained a significantly higher mean score on inter- 
nal religious motivation than did their American counterparts. This high score on religiosity might have an impact on the association between religiosity and both mental health and SWB.

The four aims of the present study were (1) to examine the differences between Kuwaiti and American college students on measures of mental health, SWB, and religiosity, (2) to examine the associations between the variables, (3) to analyze the correlation matrices to identify the main components, and (4) to explore the predictors of mental health.

\section{Method}

\section{Participants}

Two convenience samples of 154 Kuwaiti and 154 American undergraduates were recruited ( $28 \mathrm{men}$, and 126 women in both samples). The American sample was enrolled in psychology courses at the Richard Stockton College of New Jersey, with a mean age of $21.8(S D=5.0)$. The Kuwaiti sample was selected to match the American sample in the distribution by sex and was enrolled in social science courses at Kuwait University, with a mean age of 20.8 years ( $S D$ $=2.4$ ). The study was approved by the Institutional Review Boards.

\section{Measures}

(1) The Arabic Scale of Mental Health (ASMH; Abdel-Khalek, 2011b). The ASMH was developed as a trait measure for adults and adolescents. It has two equivalent versions, Arabic and English. It has 40 brief statements (e.g., "I am successful in my life", "I feel safe", and "I feel that my life has meaning") plus 10 filler items. Each item is answered on a 5-point intensity scale, anchored by 1: Not at all and 5: Very highly. The total score can range from 40 to 200, with higher scores representing higher mental health. Cronbach alpha reliabilities ranged from 0.94 to 0.96 and test-retest reliabilities ranged from 0.84 to 0.94 , indicating good internal consistency and temporal stability. Convergent, divergent, and factorial validities have been adequately demonstrated.

(2) The Self-Esteem Scale (S-ES; Rosenberg, 1989). Rosenberg has defined self-esteem as a favorable or unfavorable attitude toward oneself. The scale consists of 10 items requiring the respondent to report feelings about the self directly. The S-ES has good psychometric properties in its original English version (Blascovich \& Tomaka, 1991). The first author translated the S-ES into Arabic. Then, several cycles of revisions and corrections were carried out with the help of Ph.D. psychologists and linguists who were competent in both Arabic and English. Consistent results have been obtained with this scale in the Arab context (Abdel-Khalek \& Snyder, 2007), indicating its construct and convergent 
validity. A five-point Likert-style response format was adopted in the present version, anchored by $1=$ No and $5=$ Very much. The total score can range from 10 to 50 , with higher scores representing higher self-esteem. Cronbach's alpha reliability of the Arabic S-ES was 0.89 indicating good internal consistency.

(3) The Arabic Scale of Optimism and Pessimism (ASOP; Abdel-Khalek, 1996). The ASOP consists of two subscales in comparable Arabic and English forms to assess optimism and pessimism. Each subscale contains 15 statements to be answered on a 5-point Likert-type intensity scale as follows: 1: No, 2: A little, 3: Moderate, 4: Much, and 5: Very much. The total score can range from 15 to 75 for each subscale, with high scores denoting high optimism or pessimism. Cronbach's alpha reliabilities were 0.92-0.93 for optimism and 0.91-0.95 for Kuwaiti undergraduates. Criterion-related validity against scores on the Life Orientation Test by Scheier and Carver (1985) for the two subscales of optimism and pessimism were +0.78 , and $-0.69(d f=110, p<.0001)$, respectively, denoting good convergent and divergent validity for the two subscales. The English version of the ASOP displayed good internal consistency, convergent and divergent validity, a meaningful factorial structure and interpretable factors among American college students (Abdel-Khalek \& Scioli, 2010).

(4) The Hopelessness Scale (HS; Beck, Wessman, Lester, \& Trexler, 1974). The HS measures the cognitive component of depression. It contains 20 items answered using a true/false format, with higher scores indicating greater hopelessness. Hundreds of studies have used this scale since its publication and reported that it correlates strongly with currently suicidal ideation and behavior and predicts future suicidal behavior, both attempting and completing suicide (e.g., Beck, Steer, Kovacs, \& Garrison, 1985).

(5) Self-Rating Scales. Three separate self rating-scales (using a scale of 0 to 10) were used to assess physical health, mental health, and religiosity: (1) What is your estimation of your physical health in general? (2) What is your estimation of your mental health in general? and (3) What is your level of religiosity in general? The one week test-retest reliability of the three self-rating scales was $0.76,0.77$, and 0.88 , respectively, indicating high temporal stability, and corroborates the trait-like nature of the scores. Criterion-related validity of these scales has been adequately demonstrated (Abdel-Khalek, 2003). However, single-item self-rating scales have limitations. Foremost among them is the complexity of these constructs. Moreover, there is a need to compute the correlation between scores on these self-rating scales and social desirability (Gillings \& Joseph, 1996).

\section{Procedure}

The five questionnaires along with the three self-rating scales were administered anonymously to students during small group sessions in their class- 
rooms. The scales in Arabic were administered to the Kuwaiti students, while American students were given them in English. The return rate was 100\% for both samples. SPSS (2009) was used for the statistical analyses for both samples. Descriptive statistics, $t$ - tests, Pearson correlations, principal components analysis, and stepwise regression were used.

\section{Results}

Table 1 reports the descriptive statistics for the samples. Inspection of this table reveals that the Kuwaiti students obtained a significantly higher mean score on the religiosity self-rating scale than did their American counterparts. On the other hand, American students obtained a significantly higher mean score on the ASMH and the self-rating scales of both mental health and physical health.

TABLE 1. Mean score (M), standard deviation (SD), $t$ value and Cohen's $d$ of the scales in Kuwait and USA students

\begin{tabular}{|c|c|c|c|c|c|c|c|}
\hline \multirow[b]{2}{*}{ Scales } & \multicolumn{2}{|c|}{ Kuwaiti } & \multicolumn{2}{|c|}{ USA } & \multirow[b]{2}{*}{$t$} & \multirow[b]{2}{*}{$p$} & \multirow[b]{2}{*}{$d$} \\
\hline & $M$ & $S D$ & $M$ & $S D$ & & & \\
\hline ASMH & 147.06 & 26.06 & 153.32 & 23.90 & 2.20 & 0.029 & $0.250^{\star}$ \\
\hline Self-esteem & 32.14 & 6.32 & 32.37 & 5.07 & 0.35 & - & - \\
\hline Optimism & 57.51 & 11.11 & 57.78 & 10.75 & 0.22 & - & - \\
\hline Pessimism & 22.55 & 9.51 & 23.94 & 11.02 & 1.19 & - & - \\
\hline Hopelessness & 3.50 & 3.62 & 2.81 & 3.44 & 1.71 & - & - \\
\hline Physical health rating & 7.17 & 2.02 & 7.60 & 1.61 & 2.07 & 0.040 & $0.235^{\star}$ \\
\hline Mental health rating & 7.02 & 2.08 & 7.54 & 1.87 & 2.31 & 0.022 & $0.263^{*}$ \\
\hline Religiosity rating & 6.47 & 1.78 & 4.51 & 2.53 & 7.86 & 0.0001 & $0.896^{\star \star}$ \\
\hline
\end{tabular}

Note: ASMH-The Arabic Scale of Mental Health

* Small effect size

** Large effect size

Table 2 indicates that all the correlations between the scales were statistically significant in the Kuwaiti sample, whereas 22 out of 28 correlations $(78.6 \%)$ were significant in the American sample. The main clusters of significant correlations were centered on the ASMH with self-esteem and optimism (positively) and pessimism and hopelessness (negatively). Of importance are the higher correlations between religiosity and other scales in the Kuwait sample than in the American sample.

The correlation matrix of each country was subjected separately to a principal components analysis. On the basis of the Kaiser Unity test, that is, eigenvalues $>1.0$, two factors were identified in both countries. Then, the factors were rotated using the direct Varimax method of orthogonal rotation (SPSS, 2009). 
TABLE 2. Pearson correlations between the scales for the Kuwaiti (the upper matrix) and USA (the lower matrix) samples

\begin{tabular}{|c|c|c|c|c|c|c|c|c|}
\hline \multirow[b]{2}{*}{ Scales } & \multicolumn{8}{|c|}{ Correlations } \\
\hline & ASMH & $\begin{array}{c}\text { Self- } \\
\text { esteem }\end{array}$ & Optimism & Pessimism & $\begin{array}{l}\text { Hopeless- } \\
\text { ness }\end{array}$ & $\begin{array}{c}\text { Physical } \\
\text { health } \\
\text { rating }\end{array}$ & $\begin{array}{l}\text { Mental } \\
\text { health } \\
\text { rating }\end{array}$ & Religiosity \\
\hline ASMH & - & $.838^{\star \star}$ & $.857^{\star \star}$ & $-.589 * \star$ & $-.703^{\star \star}$ & $.374^{\star \star}$ & $.641^{\star *}$ & $.414^{\star \star}$ \\
\hline Self-esteem & $.665^{\star \star}$ & - & $.753^{\star \star}$ & $-.495^{\star \star}$ & $-.654^{\star \star}$ & $.319^{\star \star}$ & $.550 \star \star$ & $.398^{\star \star}$ \\
\hline Optimism & $.834^{\star \star}$ & $.530 \star \star$ & - & $-.570^{\star \star}$ & $-.694^{\star \star}$ & $.317^{\star *}$ & $.519^{\star \star}$ & $.393^{\star *}$ \\
\hline Pessimism & $-.515^{\star \star}$ & $-.429 \star \star$ & $-.522^{\star \star}$ & - & $.724^{\star \star}$ & $.171^{\star}$ & $-.486 * \star$ & $-.270 \star \star$ \\
\hline Hopelessness & $-.648^{\star \star}$ & $-.490 \star \star$ & $-.679 * \star$ & $.749^{\star \star}$ & - & $-.241^{\star \star}$ & $-.524^{\star \star}$ & $-.405^{\star \star}$ \\
\hline Physical health rating & g $.388^{\star *}$ & $.312^{\star \star}$ & $.259^{\star \star}$ & -.100 & -.157 & - & $.648^{\star \star}$ & $.297^{\star \star}$ \\
\hline Mental health rating & $.547^{\star \star}$ & $.472^{\star \star}$ & $.417^{\star \star}$ & $-.296^{\star \star}$ & $-.201^{\star}$ & $.556^{\star \star}$ & - & $.432^{\star \star}$ \\
\hline Religiosity & $.231^{\star \star}$ & $.206^{\star}$ & .120 & .002 & .009 & .051 & $.187^{\star}$ & - \\
\hline
\end{tabular}

Note: ASMH-The Arabic Scale of Mental Health

${ }^{*} p<.05$ (two-tailed)

${ }^{\star *} p<.01$ (two-tailed)

TABLE 3. Orthogonal (Varimax) two factor solution for the scales for Kuwaiti and USA students

\begin{tabular}{lcccc}
\hline & \multicolumn{2}{c}{ Kuwait } & \multicolumn{2}{c}{ USA } \\
Scales & Factor 1 & Factor 2 & Factor 1 & Factor 2 \\
\hline ASMH & .836 & .388 & .774 & .488 \\
Self-esteem & .789 & .336 & .613 & .466 \\
Optimism & .838 & .291 & .815 & .287 \\
Pessimism & -.797 & .008 & -.844 & .060 \\
Hopelessness & -.861 & -.192 & -.921 & .046 \\
Physical health rating & .003 & .918 & .112 & .763 \\
Mental health rating & .432 & .773 & .290 & .792 \\
Religiosity & .339 & .520 & -.037 & .469 \\
$\quad$ Eigen value & 3.70 & 2.10 & 3.30 & 1.97 \\
$\quad$ \% Variance & 46.26 & 26.29 & 41.22 & 24.64 \\
\multicolumn{1}{c}{ Total Variance } & 72.55 & 65.86 & & \\
\hline
\end{tabular}

Note: ASMH-The Arabic Scale of Mental Health

The two factors accounted for $72.55 \%$ and $65.86 \%$ of the total variance in the Kuwaiti and American samples, respectively (Table 3). In both countries, the first factor is a bipolar one and was labeled "Mental health versus hopelessness," whereas the second factor was labeled "Self-ratings of religiosity and health."

Table 4 sets out the stepwise regression results for the two countries separately, with the ASMH scores as the dependent variable. Inspection of this table indicates that the model was highly significant $(F$-ratio $=269.27$ and $116.99 ; p$ $<0.0001$ ) for the Kuwaiti and USA samples respectively. This model accounted for $84.3 \%$ and $80.1 \%$ of the total variance in the dependent variable in the two 
TABLE 4. Multiple stepwise regression for predicting the ASMH scores

\begin{tabular}{lrrrrrr}
\hline Predictors & B & $\beta$ & SE & $t$ & $p$ & $R^{2}$ \\
\hline Kuwait & & & & & & \\
Optimism & 1.117 & .476 & .117 & 9.52 & .0001 & .734 \\
Self-esteem & 1.554 & .377 & .211 & 7.37 & .0001 & .086 \\
Rating of Mental Health & 2.342 & .187 & .495 & 4.73 & .0001 & .023 \\
$\quad R^{2}$ & & & \multicolumn{2}{c}{.843} & & \\
$\quad$ F-ratio & & & & $269.27^{\star *}$ & & \\
USA & & & & & & \\
Optimism & 1.196 & .540 & .124 & 9.64 & .0001 & .696 \\
Self-esteem & .972 & .205 & .229 & 4.24 & .0001 & .069 \\
Rating of mental health & 2.305 & .180 & .564 & 4.09 & .0001 & .020 \\
Hopelessness & -1.006 & -.145 & .371 & 2.71 & .007 & .008 \\
Religiosity & .927 & .097 & .367 & 2.52 & .013 & .009 \\
$\quad R^{2}$ & & & & .801 & & \\
$\quad$ F-ratio & & & & & & \\
\hline
\end{tabular}

${ }^{\star *} p<.0001$

samples, respectively. The main predictors of the ASMH were optimism, selfesteem, and self-rating of mental health in the Kuwaiti sample, whereas the predictors in the American sample were optimism, self-esteem, self-rating of mental health, hopelessness (negatively), and religiosity, respectively.

\section{Discussion}

The study of mental health, SWB, and religiosity has become an important topic in psychology, especially in positive psychology. However, there have been few cross-cultural comparison samples. The objective of the present study was to compare samples from Kuwait and the United States.

Significant differences were evident between the two samples. The salient difference was in the self-rating scale of religiosity favoring Kuwaiti participants. This result is congruent with the report by Thorson and colleagues (1997). It is particularly noteworthy that Thorston and colleagues' study used a multi-item scale, the Hoge's (1972) Intrinsic Religious Motivation (IRM) Scale, whereas the present study administered a single-item self-rating scale assessing religiosity. However, both studies found the same result. It may be concluded that Kuwaiti students attach more importance to religion, whereas the American students are more secular. As Thorson and colleagues (1997) noted, there is less social pressure to be religious in American society.

American students had significantly higher mean scores for mental health (the multi-item ASMH and the single-item self-rating scale) and on the self- 
rating of physical health than did their Kuwaiti counterparts. The lower mean scores for mental and physical health among Kuwaiti students is in accordance with previous findings using measures of anxiety, depression, and obsessivecompulsive tendencies, rather than general mental health (Abdel-Khalek \& Lester, 2002, 2006a; Lester \& Abdel-Khalek, 1998a, 1998b, 1999).

As for the correlations between the study scales, the salient cluster of significant intercorrelations was centered on the mental health and positive traits in the two samples, that is, the ASMH, self-rating scale of mental health, selfesteem, and optimism, indicating the convergent validity of these scales. The second cluster was centered on the negative correlations between all the lastmentioned scales and both pessimism and hopelessness scales, indicating the divergent validity of the last two scales. In support of these results was the first factor extracted in both countries - "Mental health versus hopelessness".

The differences between the Kuwaiti and American students in the mean scores on the multi-item ASMH and the single item self-rating scale of mental health in the expected direction may address the criticism directed to singleitem measures. Furthermore, the ASMH and the single-item scores had approximately similar correlations with other variables in both countries, adding trustworthiness to the single item as a self-rating scale of mental health.

Regarding the religiosity self-rating scale in the Kuwaiti sample, its correlations with the other scale scores were significant and positive with mental health scores and negative with pessimism and hopelessness. In the American sample, religiosity was significantly correlated only with the ASMH and selfesteem scores, and the self-rating of mental health. This difference in the correlates of religiosity between the two countries may be due to the difference in the mean scores on religiosity of Kuwaiti (higher) and American (lower) samples. The difference was highly significant $(p<0.0001)$, with a large effect size $(d$ $=0.896)$. Notwithstanding these differences, the samples of the two countries were compatible in the positive correlation between religiosity and mental health. This relationship is congruent with the results of previous studies.

In the stepwise regression, the main predictors of mental health as assessed with the ASMH were optimism, self-esteem, and the self-rating of mental health in both countries, and, in addition, hopelessness (negative) and religiosity in the American sample.

The present results must be viewed within the limitations imposed by the data. The salient limitation is the small age range of college students, and so an important next step in this endeavor would be to recruit older age groups. Furthermore, the samples were biased in having primarily psychology students and a high proportion of female students.

By and large, it may be concluded that the salient result is the high mean score for religiosity in the Kuwait sample, and the high mean scores for mental and physical health in the American sample. Religiosity was significantly 
correlated with all the study variables in the Kuwaiti sample, whereas in the American sample religiosity was correlated only with mental health and selfesteem.

\section{References}

Abdel-Khalek, A. M. (1996). Manual for the Arabic Scale of Optimism and Pessimism. Alexandria, Egypt: Dar Al-Maarifa Al-Jamiiyah. (in Arabic).

Abdel-Khalek, A. M. (2003). The Somatic Symptoms Inventory (SSI): Development, parameters, and correlates. Current Psychiatry, 10, 114-129.

Abdel-Khalek, A. M. (2011a). Religiosity, subjective well-being, self-esteem, and anxiety among Kuwaiti Muslim adolescents. Mental Health, Religion, and Culture, 14, 129-140. http://dx.doi.org/10.1080/13674670903456463

Abdel-Khalek, A. M. (2011b). The development and validation of the Arabic Scale of Mental Health (ASMH). Psychological Reports, 109, 949-964. http://dx.doi. org/10.2466/02.03.09.PR0.109.6.949-964

Abdel-Khalek, A. M., \& Lester, D. (2002). Can personality predict suicidality? A study in two cultures. International Journal of Social Psychiatry, 48, 231-239. http:// dx.doi.org/10.1177/002076402128783271

Abdel-Khalek, A. M., \& Lester, D. (2006a). Anxiety in Kuwaiti and American college students, Psychological Reports, 99, 512-514.

Abdel-Khalek, A. M., \& Lester, D. (2006b). Optimism and pessimism in Kuwaiti and American college students. International Journal of Social Psychiatry, 52, 110-126. http://dx.doi.org/10.1177/0020764006062092

Abdel-Khalek, A. M., \& Naceur, F. (2007). Religiosity and its association with positive and negative emotions among college students from Algeria. Mental Health, Religion, and Culture, 10, 159-170. http://dx.doi.org/10.1080/13694670500497197

Abdel-Khalek, A. M., \& Scioli, A. (2010). Hope, spirituality, optimism, pessimism, and anxiety: A Kuwaiti-American comparison. Research in the Social Scientific Study of Religion, 21, 137-160. http://dx.doi.org/10.1163/9789004216464_008

Abdel-Khalek, A. M., \& Snyder, C. R. (2007). Correlates and predictors of an Arabic translation of the Snyder Hope Scale. The Journal of Positive Psychology, 2, 228-235. http://dx.doi.org/10.1080/17439760701552337

Ali, M. (2007). Impact of acculturation, ethnic identity, religiosity, and individual difference variables on the subjective well-being of Pakistani Muslims in the United States. Dissertation Abstracts International: Section B: The Science and Engineering, 67 (8-B), 4698.

Argyle, M. (2002). The psychology of happiness (2nd ed.). London: Metheun.

(a) Argyle, M., Martin, M., \& Lu, L. (1995). Testing for stress and happiness: The role of social and cognitive factors. In C. D. Spielberger \& I. G. Sarason (Eds.), Stress and emotion (Vol. 15, pp. 173-187). Washington, DC: Taylor \& Francis.

Beck, A. T., Steer, R. A., Kovacs, M., \& Garrison, B. (1985). Hopelessness and eventual suicide. American Journal of Psychiatry, 142, 559-563.

Beck, A. T., Weissman, A., Lester, D., \& Trexler, L. (1974). The measurement of pessimism: the hopelessness scale. Journal of Consulting \& Clinical Psychology, 42, 861-865. http://dx.doi.org/10.1037/h0037562

Blascovich, J., \& Tomaka, J. (1991). Measures of self-esteem. In J. P. Robinson, P. R. 
Shaver, \& L. S. Wrightsman (Eds.), Measures of personality and social psychological attitudes (pp. 115-160). San Diego: Academic Press.

Dezutter, J., Soenens, B., \& Hutsebaut, D. (2006). Religiosity and mental health: A further exploration of the relative importance of religious behaviors vs. religious attitudes. Personality and Individual Differences, 40, 807-818. http://dx.doi. org/10.1016/j.paid.2005.08.014

Diener, E. (1998). Subjective well-being and personality. In D. F. Barone, M. Hersen, \& V. B. Van Hasselt (Eds.), Advanced personality (pp. 311-334). New York: Plenum. http://dx.doi.org/10.1007/978-1-4419-8580-4_13

Diener, E., Lucas, R. E., \& Oishi (2002). Subjective well-being: The science of happiness and life satisfaction. In C. R. Snyder \& S. J. Lopez (Eds.), Handbook of positive psychology (pp. 63-73). New York: Oxford University Press.

Diener, Ed., Oishi, S., \& Lucas, R. E. (2003). Personality, culture, and subjective wellbeing: Emotional and cognitive evaluation of life. Annual Review of Psychology, 54, 403-425. http://dx.doi.org/10.1146/annurev.psych.54.101601.145056

Donahue, M. J., \& Benson, P. L. (1995). Religion and well-being in adolescents. Journal of Social Issues, 51, 145-160. http://dx.doi.org/10.1111/j.1540-4560.1995.tb01328.x

Evers, A. M. (2009). Familial religiosity buffers against the risk of poor self-esteem to depression in alternative high school students. Dissertation Abstract International: Section B: The Sciences and Engineering, 70, (3-B), 1931.

Francis, L. J., Ziebertz, H. G., \& Lewis, C. A. (2003). The relationship between religion and happiness among German students. Pastoral Psychology, 51, 273-281. http:// dx.doi.org/10.1023/A:1022529231234

Furnham, A., \& Cheng, H. (1999). Personality as predictor of mental health and happiness in the East and West. Personality and Individual Differences, 27, 395-403. http://dx.doi.org/10.1016/S0191-8869(98)00250-5

Gillings, V., \& Joseph, S. (1996). Religiosity and social desirability: Impression management and self-deceptive positivity. Personality and Individual Differences, 21, 1047-1050. http://dx.doi.org/10.1016/S0191-8869(96)00137-7

Hill, P. C., \& Pargament, K. I. (2003). Advances in the conceptualization and measurement of religion and spirituality: Implications for physical and mental health research. American Psychologist, 58, 64-74. http://dx.doi.org/10.1037/0003066X.58.1.64

Hoge, D. R. (1972). A validated intrinsic religious motivation scale. Journal for the Scientific Study of Religion, 11, 369-376. http://dx.doi.org/10.2307/1384677

Husain, Altaf (2008). The impact of religiosity ethnic identity, acculturation and discrimination on the self-esteem and academic achievement of Somali youth in the United States. Dissertation Abstracts International: Section A Humanities and Social Sciences, 69 (3-A), 1157.

Jensen, L. C., Jensen, J., \& Wiederhold, T. (1993). Religiosity, denomination, and mental health among young men and women. Psychological Reports, 73, 1157-1158. http://dx.doi.org/10.2466/pr0.1993.72.3c.1157

Jones, S. L. (1994). A constructive relationship for religion with the science and profession of psychology: Perhaps the boldest model yet. American Psychologist, 49, 184-199. http://dx.doi.org/10.1037/0003-066X.49.3.184

Koenig, H. G., King, D. E., \& Carson, V. B. (2012). Handbook of religion and health, 2nd Edition. New York: Oxford University Press.

Larson, D. B., \& Larson, S. S. (2003). Spirituality's potential relevance to physical and 
emotional health: A brief review of quantitative research. Journal of Psychology and Theology, 31, 37-51.

Lavric, M., \& Flere, S. (2008). The role of culture in the relationship between religiosity and psychological well-being. Journal of Religion and Health, 47, 164-175. http:// dx.doi.org/10.1007/s10943-008-9168-Z

Lawal, A. M. (2010). Gender, religiosity and self-esteem as predictors of sexual attitudes of students in a Nigerian tertiary institution. Gender and Behavior, 8, 2638-2648.

Lester, D., \& Abdel-Khalek, A. M. (1998a). Depression in college students in the United States and Kuwait. Psychological Reports, 83, 410.

Lester, D., \& Abdel-Khalek, A. M. (1998b). Suicidality and personality in American and Kuwaiti students. International Journal of Social Psychiatry, 44, 280-283. http://dx.doi.org/10.1177/002076409804400404

Lester, D., \& Abdel-Khalek, A. M. (1999). Manic-depression, suicidality, and obsessivecompulsive tendencies. Psychological Reports, 85, 1100. http://dx.doi.org/10.2466/ pr0.1999.85.3f.1100

Lewis, C. A. (2002). Church attendance and happiness among Northern Irish undergraduate students: No association. Pastoral Psychology, 50, 191-195. http://dx.doi. org/10.1023/A:1012948704485

Lewis, C. A., Maltby, J., \& Burkinshaw, S. (2000). Religion and happiness: Still no association. Journal of Beliefs and Values, 21, 233-236. http://dx.doi. org/10.1080/713675504

Möller, A., \& Reimann, S. (2004). [Religious dimensions and optimistic perception of the future in a stample of students]. Psychotherapie Psychosomatik Medizinische Psychologie, 54, 383-386. http://dx.doi.org/10.1055/s-2004-828290

Rew, L., \& Wong Y. J. (2006). A systematic review of associations among religiosity/ spirituality and adolescent health attitudes and behaviors. Journal of Adolescent Health, 38, 433-442. http://dx.doi.org/10.1016/j.jadohealth.2005.02.004

Ringdal, G. I. (1996). Religiosity, quality of life and survival in cancer patients. Social Indicators Research, 38, 193-211. http://dx.doi.org/10.1007/BF00300459

Roemer, M. K. (2009). Religiosity and subjective and psychological well-being in contemporary Japan. Dissertation Abstracts International, Section A: Humanities and Social Sciences, 69 (7-A). 2890.

Roman, R. E., \& Lester, D. (1999). Religiosity and mental health. Psychological Reports, $85,1088$.

Rosenberg, M. (1989). Society and the adolescent self-image. Middletown CT: Wesleyan University Press.

Rutledge, B. G. (2010). The relationship between religiosity and religious spirituality on subjective well-being. Dissertation Abstracts International: Section B The Sciences and Engineering, 70(9-B), 5870.

Scheier, M. F., \& Carver, C. S. (1985). Optimism, coping, and health: Assessment and implications of generalized outcome expectancies. Health Psychology, 4, $219-247$. http://dx.doi.org/10.1037/0278-6133.4.3.219

Schutte, J. W., \& Hosch, H. M. (1996). Optimism, religiosity, and neuroticism: A crosscultural study. Personality and Individual Differences, 20, 239-244. http://dx.doi. org/10.1016/0191-8869(95)00147-6

Seligman, M., \& Csikszentmihalyi, M. (2000). Positive Psychology: An introduction. American Psychologist, 55, 5-14. http://dx.doi.org/10.1037/0003-066X.55.1.5

Section 1.02 Seybold, K. S. (2007). Physiological mechanisms involved in religiosity/ 
spirituality and health. Journal of Behavioral Medicine, 30, 303-309. http://dx.doi. org/10.1007/s10865-007-9115-6

SPSS, Inc. (2009). SPSS: Statistical data analysis: Base 18.0, Users Guide. Chicago: SPSS Inc.

Thorson, J. A., Powell, F. C., Abdel-Khalek, A. M., \& Beshai, J. A. (1997). Constructions of religiosity and death anxiety in two cultures: The United States and Kuwait. Journal of Psychology and Theology, 25, 374-383.

Tiliouine, H., \& Belgoumidi, A. (2009). An exploratory study of religiosity, meaning in life and subjective wellbeing in Muslim students from Algeria. Applied Research in Quality of Life, 4, 109-127. http://dx.doi.org/10.1007/s11482-009-9076-8

Article II. Tiliouine, H., Cummins, R.A., \& Davern, M. (2009). Islamic religiosity, subjective well-being, and health. Mental Health, Religion and Culture, 12, 55-74. http://dx.doi.org/10.1080/13674670802118099

Veenhoven, R. (2009). How do we assess how happy we are? Tenets, implications and tenability of three theories. In A. Dutt, \& B. Radcliff (Eds.), Happiness, economics and politics. (pp. 45-69). Cheltenham, UK: Edward Elgar.

Veenhoven, R. (2010). Greater happiness for a greater number: Is that possible? If so how? In K. Sheldon, T. Kashdan, \& M. Steger (Eds.), Designing the future of positive psychology: Taking stock and moving forward. New York: Oxford University Press.

Wong, Y. J., Rew, L., \& Slaikeu, K. D. (2006). A systematic review of recent research on adolescent religiosity/spirituality and mental health. Issues in Mental Health Nursing, 27, 161-183. http://dx.doi.org/10.1080/01612840500436941 